\title{
Temporal Trends of Persistent Organic Pollutants across Africa after a Decade of MONET Passive Air Sampling
}

\section{Journal Article}

Author(s):

White, Kevin B.; Kalina, Jiří; Scheringer, Martin; Přibylová, Petra; Kukučka, Petr; Kohoutek, Jiří; Prokeš, Roman; Klánová, Jana

Publication date:

2020-07-20

Permanent link:

https://doi.org/10.3929/ethz-b-000461815

Rights / license:

Creative Commons Attribution-NonCommercial-NoDerivatives 4.0 International

Originally published in:

Environmental Science \& Technology 55(14), https://doi.org/10.1021/acs.est.0c03575 


\title{
Temporal Trends of Persistent Organic Pollutants across Africa after a Decade of MONET Passive Air Sampling
}

\author{
Kevin B. White, Jiří Kalina, Martin Scheringer,* Petra Přibylová, Petr Kukučka, Jiří Kohoutek,
} Roman Prokeš, and Jana Klánová*

Cite This: Environ. Sci. Technol. 2021, 55, 9413-9424

Read Online

ACCESS

山ll Metrics \& More

Article Recommendations

Supporting Information

ABSTRACT: The Global Monitoring Plan of the Stockholm Convention on Persistent Organic Pollutants (POPs) was established to generate long-term data necessary for evaluating the effectiveness of regulatory measures at a global scale. After a decade of passive air monitoring (2008-2019), MONET is the first network to produce sufficient data for the analysis of longterm temporal trends of POPs in the African atmosphere. This study reports concentrations of 20 POPs (aldrin, chlordane, chlordecone, DDT, dieldrin, endrin, endosulfan, $\mathrm{HBCDD}, \mathrm{HCB}$, HCHs, heptachlor, hexabromobiphenyl, mirex, PBDEs, PCBs, PCDDs, PCDFs, PeCB, PFOA, and PFOS) monitored in 9 countries (Congo, Ghana, Ethiopia, Kenya, Mali, Mauritius,

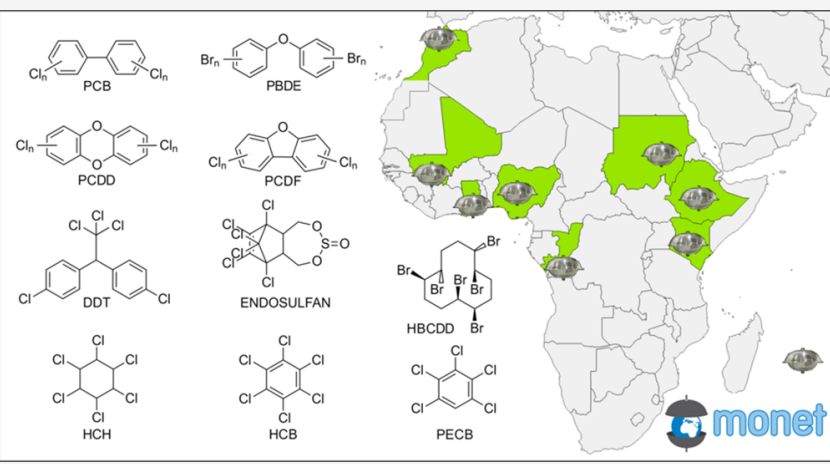
Morocco, Nigeria, and Sudan). As of January 1, 2019, concentrations were in the following ranges $\left(\mathrm{pg} / \mathrm{m}^{3}\right): 0.5-37.7\left(\sum_{6} \mathrm{PCB}\right), 0.006-0.724\left(\sum_{17} \mathrm{PCDD} / \mathrm{F}\right), 0.05-5.5\left(\sum_{9} \mathrm{PBDE}\right)$, 0.6-11.3 (BDE 209), 0.1-1.8 ( $\left.\sum_{3} \mathrm{HBCDD}\right), 1.8-138$ ( $\left.\sum_{6} \mathrm{DDT}\right), 0.1-24.3$ ( $\sum_{3}$ endosulfan), 0.6-14.6 ( $\left.{ }_{4} \mathrm{HCH}\right), 9.1-26.4$ (HCB), 13.8-18.2 (PeCB). Temporal trends indicate that concentrations of many POPs (PCBs, DDT, HCHs, endosulfan) have declined significantly over the past 10 years, though the rate was slow at some sites. Concentrations of other POPs such as $\mathrm{PCDD} / F$ s and PBDEs have not changed significantly over the past decade and are in fact increasing at some sites, attributed to the prevalence of open burning of waste (particularly e-waste) across Africa. Modeled airflow back-trajectories suggest that the elevated concentrations at some sites are primarily due to sustained local emissions, while the low concentrations measured at Mt. Kenya represent the continental background level and are primarily influenced by long-range transport.

\section{INTRODUCTION}

Following the entry-into-force of the Stockholm Convention (SC) in 2004 to restrict and eliminate the production of persistent organic pollutants (POPs), a Global Monitoring Plan (GMP) was devised to evaluate the effectiveness of regulatory measures at regional and global scales. At the time, regions such as North America and Western Europe already had established air monitoring networks that had been sampling POPs in some capacity since at least the 1990s. However, these networks were based on active air samplers that were operating at meteorological stations and could not be as easily deployed in regions such as Africa, where data were sparse due to limitations in infrastructure and funding. Furthermore, studies of POPs in Africa had historically focused on matrices other than air, such as water, sediment, soil, food, livestock, and human blood and milk. ${ }^{1-7}$ To address this gap, the European MONET passive air monitoring network (RECETOX, Masaryk University) ${ }^{8}$ was expanded into several countries across Africa in 2008 to generate consistent data for the continent. ${ }^{9,10}$ In comparison to active samplers, passive air samplers are cheap, are simple to use, and do not require electricity, which made them ideal for capacity building in Africa. ${ }^{11}$ Good comparability of results between MONET passive air samplers and colocated active air samplers has been observed in Europe, ${ }^{12,13}$ as well as recently in Africa; ${ }^{14}$ thus, passive samplers are a suitable alternative in regions where widespread active sampling is unfeasible.

Air monitoring across Africa was initially supplemented by the GAPS network (Environment and Climate Change Canada) ${ }^{15-17}$ with passive air sampling results from MONET and GAPS used in the SC GMP Regional Monitoring Reports for Africa in $2009^{18}$ and 2015. ${ }^{19}$ Characterization of baseline atmospheric concentrations was made possible by these sampling campaigns, but the lack of adequate financial resources and infrastructure to ensure continuous long-term monitoring

Special Issue: POPs on the Global Scale: Sources, Distribution, Processes, and Lessons Learned for Chemicals Management

Received: June 3, 2020

Revised: September 30, 2020

Accepted: October 6, 2020

Published: October 23, 2020

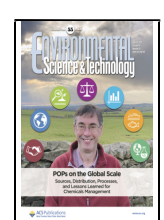


Table 1. MONET Sampling Sites in Africa Included in This Study

\begin{tabular}{|c|c|c|c|c|c|c|c|}
\hline site & country & latitude & longitude & elevation ( $\mathrm{m}$ a.s.l.) & type & monitoring & no. of samples \\
\hline Abetefi & Ghana & 6.683 & -0.750 & 590 & rural/agricultural & $2010-2018$ & 29 \\
\hline Asela & Ethiopia & 7.950 & 39.117 & 2330 & suburban & $2008-2019$ & 24 \\
\hline Bamako & Mali & 12.100 & -8.033 & & rural/agricultural & 2016-2019 & 10 \\
\hline Brazzaville & Congo & -4.281 & 15.244 & 300 & urban & $2008-2019$ & 39 \\
\hline Khartoum & Sudan & 15.564 & 32.514 & 390 & urban/industrial & $2008-2014$ & 20 \\
\hline Mt. Kenya & Kenya & -0.030 & 37.220 & 3680 & remote/high altitude & $2008-2018$ & 19 \\
\hline Rabat & Morocco & 33.925 & -6.758 & & urban & 2014-2016 & 10 \\
\hline Reduit & Mauritius & -20.230 & 57.497 & 310 & suburban & $2008-2019$ & 34 \\
\hline Sheda & Nigeria & 8.881 & 7.062 & 230 & rural/agricultural & $2008-2017$ & 29 \\
\hline
\end{tabular}

necessary for evaluation of trends was highlighted as a key concern. ${ }^{19}$ As a result of gaps and inconsistencies in previous monitoring activities, until now there has been a lack of sufficient long-term data with adequate spatial coverage necessary for evaluating the effectiveness of the SC in Africa. ${ }^{19,20}$ This is the first study to report continuous long-term temporal trends of atmospheric POP concentrations across Africa, as well as the first study to report atmospheric concentrations of some "new" SC POPs in Congo, Ghana, Ethiopia, Kenya, Mali, Mauritius, Morocco, Nigeria, and Sudan. A back-trajectory analysis of airflows sampled at each site was also performed to identify possible source regions and assess the continental coverage of the MONET network.

\section{METHODS}

All air sampling data reported in this study were taken from the MONET passive monitoring network and are freely accessible online through the Genasis Database ${ }^{21}$ hosted by RECETOX at Masaryk University in Brno, Czech Republic. This study focused on the seven MONET sites in Africa with long-term air monitoring since the original sampling campaigns in 2008 and 2010. Sampling data at these sites covered a period of 6 years or more and were used to calculate temporal trends of atmospheric POP concentrations. Two new sites, established in Morocco (2014) and Mali (2016), were also included to augment the discussion of concentrations and potential sources but did not have enough data to calculate temporal trends. The MONET sites included in this study are given in Table 1. Inactive MONET sites in Africa are given in Table S1.

Passive Sampling. MONET passive samplers consist of a polyurethane foam (PUF) disk suspended between two stainless steel bowls that protect the PUF disk from dry and wet deposition, as well as sunlight, but still allow penetration of ambient air. MONET passive sampler design characteristics are given in Table S2. During the initial 2008 campaign, MONET passive samplers were deployed for continuous 28 day intervals; since 2010, they have been deployed for continuous 84 day intervals. While MONET sampling in Africa has been ongoing since 2008, some gaps in monitoring have occurred over the past decade at some sites. The sampling regime and availability of data for each compound group and site are depicted in Figure S1.

Chemical Analysis. After each exposure period, PUF disks were collected and shipped to RECETOX, where they were analyzed in the Trace Analytical Laboratory. Across the MONET network in Africa, 16 of the currently listed SC POPs have been included in continuous routine monitoring since 2008/2010: aldrin, chlordane, dichlorodiphenyltrichloroethane (DDT), dieldrin, endrin, endosulfan, hexabromocyclododecane (HBCDD), hexachlorobenzene (HCB), hexachlor- ocyclohexanes (HCHs), heptachlor, mirex, polybrominated diphenyl ethers (PBDEs), polychlorinated biphenyls (PCBs), polychlorinated dibenzo- $p$-dioxins (PCDDs), polychlorinated dibenzofurans (PCDFs), and pentachlorobenzene (PeCB). Four additional POPs were monitored from 2010-2012: chlordecone, hexabromobiphenyl, perfluorooctanoic acid (PFOA), and perfluorooctanesulfonic acid (PFOS), except at Mt. Kenya, where PFOA and PFOS were monitored from 2010 to 2016. Refer to section 4.5 (Limited Monitoring POPs) of the Supporting Information for atmospheric concentrations of these four POPs across Africa, as well as a 6 year temporal trend for PFOS at Mt. Kenya. A summary of all POPs included in this study and the availability of MONET sampling data for each is provided in Table S3, and an overview of standard analytical methods is presented in Table S4. Detailed information on MONET passive air sampling, chemical analysis, and instrumental methods is provided in section 2 (Analytical Methods) of the Supporting Information.

Derivation of Air Concentrations. Concentrations of POPs in each PUF disk ( $\mathrm{pg} / \mathrm{PUF}$ ) were converted to concentrations in air $\left(\mathrm{pg} / \mathrm{m}^{3}\right)$ using the standard GAPS template model for estimating effective air sampling volumes of passive PUF samplers. ${ }^{22}$ Model input parameters specific to MONET samplers are given in Table S2. Since there were no consistent local meteorological measurements over the 10 year monitoring period at most of the sites, temperature inputs were generated from the MERRA-2 model (NASA), ${ }^{23}$ as previously described. $^{14,24}$ A more robust GAPS model for estimating effective passive air sampling volumes has recently been proposed; ${ }^{24}$ however, in its current state it could not be applied to all of the POPs included in this study. A detailed investigation of the accuracy and comparability of results between the two GAPS models at sites in Africa has been reported by BohlinNizzetto et al. ${ }^{14}$ In general, the models predicted very similar air concentrations; ${ }^{14}$ thus, the model selection is not expected to significantly influence the long-term temporal trends at the sites included in this study. For now, the original GAPS model remains the standard global method for reporting air concentrations from passive sampling to the SC GMP. ${ }^{25}$

Temporal Trend Analysis. Each concentration in the data series represents one individual PUF sample, with the middle date of each sample's exposure period selected to represent the point in time. Time series with less than 30\% left-censored values (concentrations below the instrumental limit of quantification, LOQ) were further examined for temporal trends on the basis of previously established criteria. ${ }^{13}$ Temporal trends were determined by linear regression fits on logtransformed concentrations using the Theil-Sen estimator, providing rate constants (\% annual change) and halving times of the compound in air. The statistical significance of the calculated 


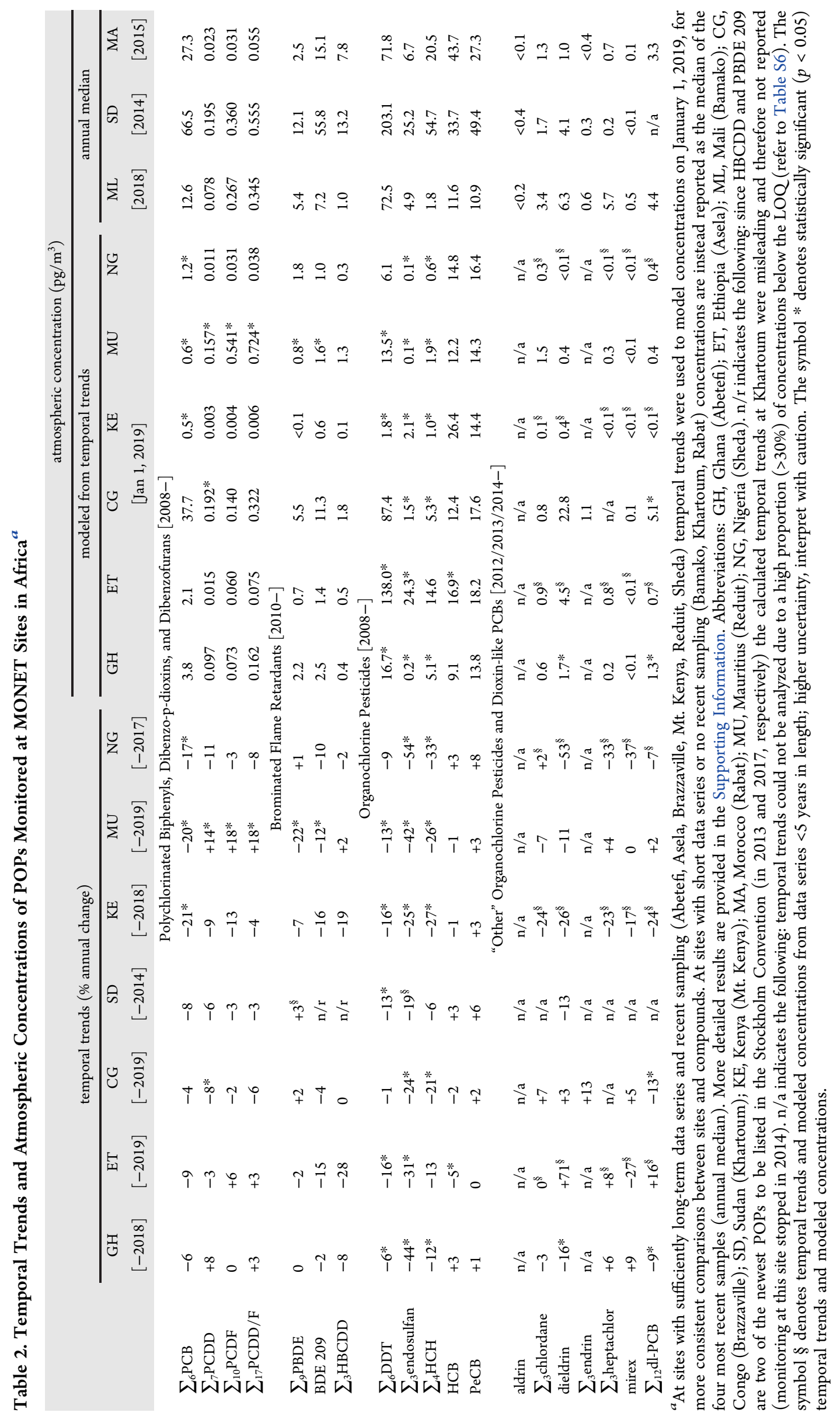



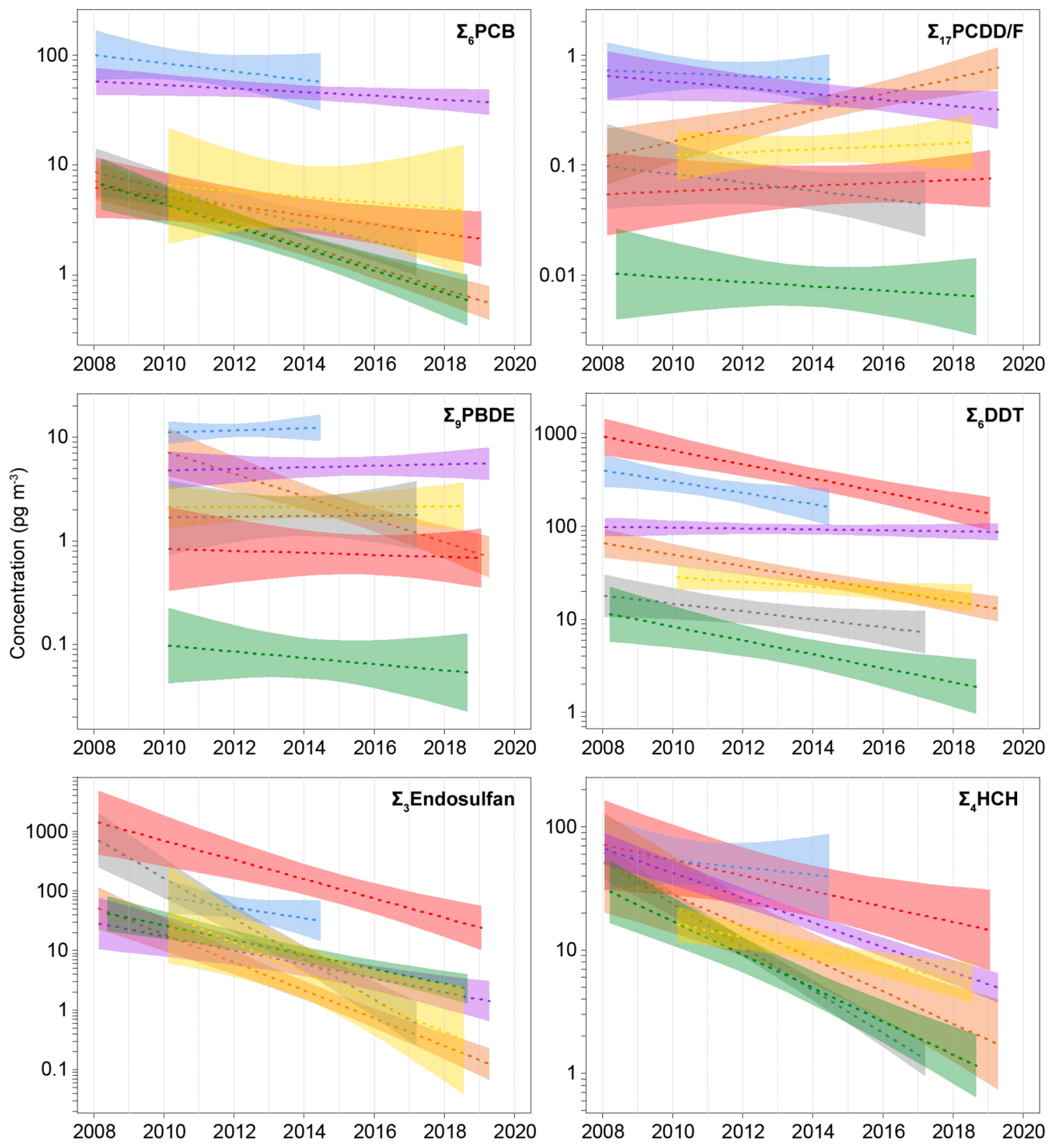

\begin{tabular}{|llll|}
\hline$\square$ Abetefi (GH) & $\square$ Brazzaville (CG) & $\square$ Mt. Kenya (KE) & $\square$ Sheda (NG) \\
$\square$ Asela (ET) & $\square$ Khartoum (SD) & $\square$ Reduit (MU)
\end{tabular}

Figure 1. Temporal trends of atmospheric POP concentrations at MONET sites in Africa with long-term monitoring (2008-2019): $\sum_{6} \mathrm{PCB}$ (28, 52, $101,138,153,180) ; \sum_{17}$ PCDD /F (7 PCDDs, 10 PCDFs); $\sum_{9} \operatorname{PBDE}\left(28,47,66,85,99,100,153,154,183 ; 209\right.$ excluded); $\sum_{6}$ DDT (o,p'-DDD, o, p $^{\prime}$ DDE, o, $\mathrm{p}^{\prime}$-DDT, p, $\mathrm{p}^{\prime}$-DDD, p, $\mathrm{p}^{\prime}$-DDE, $\mathrm{p}, \mathrm{p}^{\prime}$-DDT); $\sum_{3}$ endosulfan $\left(\alpha, \beta\right.$, sulfate); $\sum_{4} \mathrm{HCH}(\alpha, \beta, \gamma, \delta)$. Dotted lines depict average exponential trends (percent change per year), and shaded areas depict the $95 \%$ confidence intervals. For visual clarity individual sample concentrations are not shown.

trends was then assessed using the nonparametric MannKendall test. The strengths and limitations of these methods for calculating temporal trends from passive air sampling data have been described in detail by Kalina et al. ${ }^{13}$ Finally, due to the different lengths and end dates of sampling regimes (Figure S1), the temporal trends were used to extrapolate or interpolate an atmospheric concentration on January 1, 2019, for all sites/ compounds for a more consistent comparison of timedependent data.
Back-Trajectory Analysis. To evaluate the spatial coverage and sources of air sampled by the MONET network, threedimensional air mass back-trajectories were modeled at each site for $120 \mathrm{~h}$, every $3 \mathrm{~h}$, for 365 days (January 1 to December 31, 2018) at an above-ground arrival height of $200 \mathrm{~m}$ using HYSPLIT (v.4.2.0, NOAA). ${ }^{26}$ These model settings were consistent with previous HYSPLIT modeling of backtrajectories at MONET sites in Africa and ensured that the air masses began in the mixing layer of the atmosphere. ${ }^{10,27}$ All individual back-trajectories generated by HYSPLIT were 
converted to GIS shapefiles and imported into ArcGIS (v.10.7, Esri) for spatial analysis. To account for the speed and atmospheric residence time of air masses, each continuous back-trajectory line was transformed into 120 hourly points. This transformation allowed for the subsequent application of a kernel density tool to the combined back-trajectory air mass points from all sampling sites in order to create a heat map of the continental density and spatial coverage of modeled airflows sampled by the MONET network over the course of an entire year. Individual monthly back-trajectory maps were also generated for each site to evaluate potential seasonal changes in the coverage and sources of airflows. Refer to section 5 (BackTrajectories) of the Supporting Information.

\section{RESULTS AND DISCUSSION}

Temporal Trends of Atmospheric Concentrations. Passive air monitoring of PCBs, PCDD/Fs, and OCPs (DDT, endosulfan, $\mathrm{HCHs}, \mathrm{HCB}, \mathrm{PeCB}$ ) has been ongoing since 2008 at all long-term MONET sites in Africa except for Abetefi (since 2010), and as a result the temporal trends for these compounds ranged from 8.4 years at Abetefi $(n=29)$ to 11.2 years at Reduit $(n=34)$. Khartoum was also included in the temporal trend analysis, though the trends were shorter ( 6.4 years, $n=20)$, since monitoring stopped at this site in 2014. Monitoring of PBDEs (including BDE 209) and HBCDD began in 2010, and as a result the temporal trends for these compounds were approximately 2 years shorter, ranging from 4.4 years at Khartoum $(n=14)$ to 9.2 years at Reduit $(n=32)$. Due to poor instrumental detection of the "other" OCPs (aldrin, chlordane, dieldrin, endrin, heptachlor, mirex) at most sites during the initial campaigns (2008-2012), data series for these compounds began after 2012, corresponding to changes in instrumentation resulting in improved detection. Following these changes, routine monitoring of dioxin-like PCBs (dlPCBs) also began at all sites. Refer to section 2 (Analytical Methods) of the Supporting Information. As a result of these analytical changes and the later start of monitoring, temporal trends for the "other" OCPs and dl-PCBs were the shortest, ranging from 3.0 years at Sheda $(n=13)$ to 6.5 years at Abetefi $(n=20)$, and had a much greater degree of uncertainty.

Since multiple analytes were monitored in air for most POPs, these compounds are presented as sums: 6 indicator $\mathrm{PCB}$ congeners $\left(\sum_{6} \mathrm{PCB}\right), 12$ dioxin-like PCB congeners $\left(\sum_{12} \mathrm{dl}-\right.$ PCB $), 7$ dioxins $\left(\sum_{7}\right.$ PCDD ), 10 furans $\left(\sum_{10}\right.$ PCDF $)$, and all 17 homologues together $\left(\sum_{17} \mathrm{PCDDF}\right), 9 \mathrm{PBDE}$ congeners ( $\sum_{9}$ PBDE; excluding BDE 209), 3 HBCDD isomers ( $\left.\sum_{3} \mathrm{HBCDD}\right), 6 \mathrm{DDT}$ analytes $\left(\sum_{6} \mathrm{DDT}\right), 4 \mathrm{HCH}$ isomers ( $\left.\sum_{4} \mathrm{HCH}\right), 3$ chlordane analytes $\left(\sum_{3}\right.$ chlordane $), 3$ endosulfan analytes ( $\sum_{3}$ endosulfan $), 3$ endrin analytes $\left(\sum_{3}\right.$ endrin $)$, and 3 heptachlor analytes ( $\sum_{3}$ heptachlor). Individual compounds within each sum are given in Table S5. A summary of temporal trends and atmospheric concentrations of POPs at each site is provided in Table 2 . Values from data series shorter than 5 years are marked with the symbol $\S$ and should be interpreted with caution. ${ }^{13}$ Trends and concentrations for individual compounds, as well as more detailed statistical results, are provided in the Supporting Information.

PCBs. A decreasing trend was observed in the atmospheric $\sum_{6} \mathrm{PCB}$ concentrations at each site, with the steepest and most statistically significant annual decreases at Mt. Kenya, Reduit, and Sheda $(17-21 \%, p<0.01)$. Although $\sum_{6} \mathrm{PCB}$ also decreased at the other sites, the rates of decline were slower and were not statistically significant (4-9\%; Figure 1, $\left.\sum_{6} \mathrm{PCB}\right)$.
Modeled January 1, 2019, concentrations ranged from $0.5 \mathrm{pg} /$ $\mathrm{m}^{3}$ at Mt. Kenya to $37.7 \mathrm{pg} / \mathrm{m}^{3}$ at Brazzaville. A modeled concentration could not be predicted for Khartoum with certainty, since monitoring at this site stopped in 2014; however, extrapolating the temporal trend forward by 5 years provided a value of $38.5 \mathrm{pg} / \mathrm{m}^{3}$, similar to that for Brazzaville. Concentrations at the two remaining sites with insufficient data to derive temporal trends, Bamako and Rabat, are reported as the median of the most recent year of samples $(n=4)$ in Table 2 and are within the range of the other sites at $12.6 \mathrm{pg} / \mathrm{m}^{3}$ (2018) and $27.3 \mathrm{pg} / \mathrm{m}^{3}(2015)$, respectively. There is a significant lack of current atmospheric PCB data in Africa, with the most recent studies still reporting concentrations from air sampling campaigns performed approximately 10 years ago. ${ }^{28,29}$ At the time, PCB concentrations varied widely across the continent $\left(\sum \mathrm{PCB}\right.$ of $\left.2-2000 \mathrm{pg} / \mathrm{m}^{3}\right) .^{9,28-31}$ Atmospheric concentrations at MONET sites as of 2019 fall at the lower end of those in these previous studies, consistent with the decreasing trends over the past 10 years. However, the slow rate of decline and elevated concentrations still observed at certain sites, particularly Brazzaville, are indicative of continued PCB emissions.

In Africa, atmospheric PCB concentrations have been attributed to emissions from sources similar to those in the rest of the world, including leakage from electrical transformers and revolatilization from landfills and other waste. ${ }^{1,30}$ However, the prevalence of unregulated imports, crude recycling, and open burning of waste (particularly electronic waste, e-waste) has been identified as the major source of ongoing $\mathrm{PCB}$ emissions across Africa, ${ }^{28-32}$ with PCB concentrations as high as $11000 \mathrm{pg} / \mathrm{m}^{3}$ measured in e-waste plumes in Agbogbloshie, Ghana. ${ }^{29} \mathrm{PCB}$ emission sources are generally congener-specific, with the less chlorinated PCBs (28 and 52) being the most volatile and therefore most associated with revolatilization from landfills, poorly stored or disposed waste, and contaminated soil. $^{28,33}$ Conversely, emissions of the more chlorinated PCBs have been attributed to combustion processes. ${ }^{33}$ Historical production and use of PCBs in Africa was limited; thus, emissions across the continent are predominantly attributed to imported products. ${ }^{29-31}$ However, global technical PCB formulations and their congener contents were diverse, ${ }^{34}$ making it difficult to assess emission sources on the basis of specific congener profiles in Africa. Nevertheless, some conclusions can still be drawn from the significant variations observed in the congener profiles contributing to $\sum_{6} \mathrm{PCB}$ concentrations at MONET sites (Table S7A). For example, concentrations at Mt. Kenya and Reduit consisted solely of PCBs 28 and 52 (approximately 50\% each). Since these are the two most remote MONET sites in Africa, the lack of detection of any of the more chlorinated PCBs, along with the lowest measured concentrations of PCB 28 and $52\left(0.2 \mathrm{pg} / \mathrm{m}^{3}\right.$ at both sites), suggests that the $\mathrm{PCB}$ concentrations measured at these sites may be representative of the continental background and primarily influenced by long-range transport (LRT). ${ }^{9,10}$ This is supported by similar atmospheric PCB profiles and concentrations measured at a remote site off the coast of West Africa attributed to LRT (PCBs 28 and 52 both $0.2 \mathrm{pg} / \mathrm{m}^{3}$ as well). ${ }^{35}$ Conversely, elevated $\sum_{6} \mathrm{PCB}$ concentrations at Bamako and Rabat had the lowest proportion of PCBs 28 and 52, and the highest proportion of the more chlorinated congeners (PCBs 138,153 , and 180), suggesting a stronger influence of local combustion sources as observed at other urban sites in Africa. $^{28,29}$ 
PCDD/Fs. Atmospheric $\sum_{17} \mathrm{PCDD} / \mathrm{F}$ concentrations remained relatively constant over the monitoring period, with trends ranging from an annual decrease of $8 \%$ at Sheda to an annual increase of $3 \%$ at Abetefi and Asela. The one exception was a strong and statistically significant annual increase at Reduit $(18 \%, p<0.01)$ corresponding to a highly elevated modeled January 1, 2019, concentration of $724 \mathrm{fg} / \mathrm{m}^{3}$ (Figure 1, $\left.\sum_{17} \mathrm{PCDD} / \mathrm{F}\right)$. Modeled concentrations at the remaining sites ranged from $6 \mathrm{fg} / \mathrm{m}^{3}$ at Mt. Kenya to $322 \mathrm{fg} / \mathrm{m}^{3}$ at Brazzaville, with the annual median at Rabat (2015) falling in this range as well $\left(55 \mathrm{fg} / \mathrm{m}^{3}\right)$. Annual median concentrations at the remaining two sites, Bamako (2018) and Khartoum (2014), were also significantly elevated (345 and $555 \mathrm{fg} / \mathrm{m}^{3}$, respectively). Although sum concentrations of PCDD/Fs are often reported in units of toxicity equivalence (TEQ), they are reported here in units of $\mathrm{fg} / \mathrm{m}^{3}$ for consistency with the other POPs and to facilitate source evaluation of individual homologues. Due to the prohibitive cost of $\mathrm{PCDD} / \mathrm{F}$ sample analysis, atmospheric concentrations of PCDD/Fs in Africa have only been reported by the large international monitoring networks after passive sampling campaigns approximately 10 years ago. Concentrations from the initial MONET sampling campaign in 2008 (median $\sum \mathrm{PCDD} / \mathrm{F}$ of $55 \mathrm{fg} \mathrm{TEQ} / \mathrm{m}^{3}$ ) ${ }^{9}$ were similar to those measured in a subsequent sampling campaign by the United Nations Environment Program (UNEP) in Africa from 2010 to 2013 (median $\sum$ PCDD/F of $51 \mathrm{fg}$ TEQ $/ \mathrm{m}^{3}$; range $18-532 \mathrm{fg}$ $\left.\mathrm{TEQ} / \mathrm{m}^{3}\right){ }^{31}$ The one exception was an independent passive sampling campaign of PCDD/Fs at primarily industrial sites in northern Algeria during the same period (2008-2009). Concentrations of $\sum \mathrm{PCDD} / \mathrm{F}$ at these sites ranged from 210 to $780 \mathrm{fg} \mathrm{TEQ} / \mathrm{m}^{3},{ }^{36}$ similar to the upper range of concentrations measured during the MONET and UNEP campaigns at urban and industrial sites. The lack of change in $\sum_{17}$ PCDD/F concentrations over the past 10 years, in addition to the significant increase at Reduit, suggests that MONET sites are affected by ongoing emissions.

Atmospheric concentrations of PCDD/Fs in Africa have been attributed to emissions from industry, obsolete pesticide stockpiles, waste incineration, and open burning of ewaste, ${ }^{2,3,37}$ as well as anthropogenic burning of biomass and natural fires at rural and agricultural sites. ${ }^{27}$ Similar to the case for PCBs, sources of PCDD/Fs in Africa are highly homologue specific. Emissions from refineries and waste incineration plants in Algeria are dominated by $\mathrm{HpCDF}$ and $\mathrm{HxCDF}$ $(1,2,3,4,6,7,8-\mathrm{HpCDF}$ alone represents $41-61 \%$ of the $\sum$ PCDF concentration in air at these sites), ${ }^{36}$ while concentrations in soil at an e-waste recycling site at Agbogbloshie in Ghana suggest that emissions from the open burning of these materials are dominated by TCDF $(26 \%$ of $\sum \mathrm{PCDD} / \mathrm{F}$ ) and PeCDFs. ${ }^{37}$ The average composition of $\sum_{17} \mathrm{PCDD} / \mathrm{F}$ concentrations across the MONET sites was dominated by OCDD (20\%), 2,3,7,8-TCDF (13\%), $1,2,3,4,6,7,8-\mathrm{HpCDF}$ (11\%), 2,3,4,7,8-PeCDF (11\%), and $1,2,3,7,8-\mathrm{PeCDF}$ (10\%). Average contributions of the remaining PCDD/F homologues fell below $10 \%$, with HxCDDs, PeCDDs, and TCDD all particularly low ( $<2 \%$ each; Table S7B). This profile is relatively similar to those of GAPS passive sampling sites across Latin America (dominated by OCDD and 2,3,7,8TCDF), which were primarily attributed to biomass burning (large-scale deforestation). ${ }^{38}$ However, the larger contribution of HpCDF and PeCDF homologues at many MONET sites in Africa suggests they are affected by waste incineration as well, though PCDD/F emission profiles can still vary depending on the type of waste. ${ }^{39}$ While this complexity makes it difficult to identify specific sources when some sites in Africa are likely influenced by several, it can provide some explanation for the differences observed in site-specific profiles. For example, Bamako, Khartoum, and Reduit had the highest $\sum_{17} \mathrm{PCDD} / \mathrm{F}$ concentrations as well as the highest relative proportions of $\mathrm{HxCDD} / \mathrm{Fs}$, indicating combustion. Conversely, concentrations at Brazzaville were also elevated but were dominated by just OCDD and $1,2,3,4,6,7,8-\mathrm{HpCDD}$ (53\% together). In fact, Brazzaville and Abetefi were the only two sites where $\sum_{7}$ PCDD exceeded $\sum_{10} \mathrm{PCDF}$; at all other sites $\sum_{10} \mathrm{PCDF}$ was approximately $2-4$ times higher than $\sum_{7} \mathrm{PCDD}$, suggesting different emission sources between these two groups. Furthermore, the $\sum_{17} \mathrm{PCDD} / \mathrm{F}$ concentration profile at Mt. Kenya was unique, with a significantly higher proportion of OCDF $(21 \%)$ in comparison to all other sites $(0-5 \%)$ but similarly high proportions of OCDD (22\%) and 1,2,3,4,6,7,8HpCDF (18\%). These three homologues are by far the most persistent PCDD/Fs in air, ${ }^{40,41}$ providing further evidence that the low POP concentrations measured at Mt. Kenya represent the continental background and are primarily influenced by LRT.

PBDEs. Apart from a strong and significant decrease in atmospheric $\sum_{9}$ PBDE concentrations at Reduit (22\% annual decrease; $p<0.01)$ and a moderate decrease at Mt. Kenya (7\% annual decrease), no statistically significant trend was observed at any other site (Figure 1, $\sum_{9} \mathrm{PBDE}$ ). At these other sites, $\sum_{9} \mathrm{PBDE}$ concentrations remained relatively constant over the entire monitoring period, with trends ranging from a $2 \%$ annual decrease at Asela to a 3\% increase at Khartoum. Similarly, no significant changes in PBDE concentrations were observed between global GAPS air sampling campaigns in 2005 and $2014,{ }^{42}$ suggesting a lack of atmospheric decline consistent with the results of this study. Modeled January 1, 2019, $\sum_{9} \mathrm{PBDE}$ concentrations ranged from $0.05 \mathrm{pg} / \mathrm{m}^{3}$ at Mt. Kenya to $5.5 \mathrm{pg} /$ $\mathrm{m}^{3}$ at Brazzaville. The annual median concentration at both Bamako $\left(5.4 \mathrm{pg} / \mathrm{m}^{3}, 2018\right)$ and Rabat $\left(2.5 \mathrm{pg} / \mathrm{m}^{3}, 2015\right)$ fell within this range but was elevated at Khartoum $\left(12.1 \mathrm{pg} / \mathrm{m}^{3}\right.$, 2014). Atmospheric concentrations of PBDEs at MONET sites are within the range of those measured by GAPS in 2014 at a background site in South Africa $\left(\sum_{14} \mathrm{PBDE}\right.$ ranging $0.1-1.1 \mathrm{pg} /$ $\left.\mathrm{m}^{3}\right)$ as well as globally $\left(\sum_{14}\right.$ PBDE ranging $\left.0.1-93 \mathrm{pg} / \mathrm{m}^{3}\right),{ }^{42}$ at the lower end of those measured in Uganda from 2008 to 2010 $\left(\sum 9\right.$ PBDE ranging $\left.3.3-252 \mathrm{pg} / \mathrm{m}^{3}\right)$, ${ }^{43}$ and much lower than those measured at suburban sites in South Africa in 2016/2017 $\left(\sum_{9} \mathrm{PBDE}\right.$ ranging $\left.100-284 \mathrm{pg} / \mathrm{m}^{3}\right) .{ }^{44}$ However, it is important to note that the atmospheric $\sum$ PBDE concentrations in the studies in Uganda and South Africa included BDE 209, whereas the MONET and GAPS sums excluded it. Moderately steep declines were observed in the temporal trends of BDE 209 at MONET sites in comparison to $\sum_{9} \mathrm{PBDE}$, ranging from 10 to $16 \%$ annual decreases at most sites, while Abetefi and Brazzaville remained relatively constant $(2-4 \%$ annual decreases; Figure S2A). At all sites except Sheda, the concentration of BDE 209 alone was equivalent to or significantly greater than the sum of all other congeners, with modeled January 1, 2019, concentrations ranging from $0.6 \mathrm{pg} / \mathrm{m}^{3}$ at Mt. Kenya to $11.3 \mathrm{pg} / \mathrm{m}^{3}$ at Brazzaville. These concentrations were also within the range reported globally for BDE 209 by GAPS in $2014(<1-52 \mathrm{pg} /$ $\left.\mathrm{m}^{3}\right),{ }^{42}$ at the lower end of those measured in Uganda from $2008-2010\left(<1.6-168 \mathrm{pg} / \mathrm{m}^{3}\right),{ }^{43}$ and still lower than the minimum concentration measured at sites in South Africa in $2016 / 2017\left(80 \mathrm{pg} / \mathrm{m}^{3}\right){ }^{44}$ 
Atmospheric concentrations of PBDEs in Africa have been primarily attributed to emissions from the dumping, recycling, and open burning of imported waste consumer products, particularly electronics (e-waste). ${ }^{5,43}$ Furthermore, since these compounds were never extensively produced in Africa, ${ }^{44}$ industrial emissions are expected to be negligible. These emission patterns are apparent from an air monitoring study in South Africa that observed high concentrations of PBDEs (including BDE 209) at a landfill site and moderate concentrations at a densely populated urban site but low and similar concentrations at both industrial and sparsely populated suburban sites. ${ }^{44}$ Unlike the case for PCBs and PCDD/Fs, there was little variation in the relative profiles of individual PBDE congeners in the atmosphere, with BDE 47 and 99 dominating the $\sum_{9} \mathrm{PBDE}$ concentrations at every MONET site (average $40 \%$ and $23 \%$, respectively; Table S7C). These two congeners comprised the majority of the pentaBDE formulations (87$88 \%)^{45}$ and now dominate atmospheric PBDE congener profiles across Africa, ${ }^{43,44}$ as well as over continents ${ }^{42}$ and oceans ${ }^{46,47}$ globally. The global atmospheric prevalence of BDE 209 varies depending on region and historical use of decaBDE (92-97\% BDE 209), ${ }^{45}$ with concentrations generally below detection in Europe but still dominating PBDE profiles at some sites in North America as of 2014, ${ }^{42}$ as well as in Africa. ${ }^{43,44}$ When BDE 209 is included in the sum concentration of all PBDE congeners $\left(\sum_{10} \mathrm{PBDE}\right)$, it dominates the profile at all MONET sites (average 68\%; BDE 47 and 99 fall to $14 \%$ and $7 \%$, respectively; Table S7D and Figure S2B). This profile is consistent with landfilling and open burning of e-waste, as decaBDE was predominantly used in electronics, and the primary atmospheric sources of BDE 209 are thought to be particle-bound emissions from landfills and combustion. ${ }^{48}$ Interestingly, BDE 28 was the fourth or fifth most prevalent congener at all sites (either followed or preceded by BDE 100 or 183). While BDE 100 was the third-most prevalent congener in pentaBDE $(8-13 \%)$ and BDE 183 was the main congener in octaBDE (13-42\%), BDE 28 was not a major congener in any of the commercial PBDE formulations $(\leq 2.5 \%) .{ }^{45}$ Despite this, a recent study found BDE 28 to be the most dominant congener in soils near a crude ewaste recycling site in Agbogbloshie, Ghana (followed by BDE 209 and 47), attributed to debromination of other congeners during open burning. ${ }^{49}$ Since BDE 28 is one of the most volatile congeners, revolatilization from these soils is likely and provides further evidence that the relatively constant atmospheric PBDE concentrations across Africa over the past decade are heavily influenced by e-waste emissions.

OCPs. Due to their widespread use in Africa for the control of agricultural pests as well as disease vectors, organochlorine pesticides (OCPs) are among the most environmentally prevalent and widely studied POPs across the continent. ${ }^{6,7}$ Despite being listed in the SC, many OCPs are still applied across Africa due to poor regulatory enforcement and pest management practices, as well as exempted use for public health indoor residual spraying (e.g., DDT). ${ }^{9,31,50}$ The illicit disposal, storage, and use of obsolete stockpiles also poses a significant challenge. ${ }^{6,7,50,51}$ Of all currently listed OCPs, DDT, endosulfan, and $\mathrm{HCHs}$ had not only the highest initial atmospheric burdens across MONET sites in Africa but also the most significant declines over the past 10 years.

DDT is consistently detected at elevated levels in the atmosphere across Africa, ${ }^{50,52,53}$ with maximum concentrations in some studies ranging $1880-8000 \mathrm{pg} / \mathrm{m}^{3}$. $9,31,54$ The atmospheric burden of DDT has been attributed not only to its widespread use in agriculture across the continent but also to its current exemption under the SC for the control of malaria vectors. $^{9,31}$ As a result, a shift in the most elevated concentrations from rural to urban sites has been observed, ${ }^{52}$ likely due to its continued use for indoor residual spraying., ${ }^{9,50}$ Several countries have also reported large stockpiles in case of future malaria outbreaks, while obsolete dumping sites have resulted in atmospheric DDT concentrations as high as $10^{5} \mathrm{pg} /$ $\mathrm{m}^{3}$.,31 There is also the potential for these obsolete or public health stockpiles to be misappropriated for illicit use in agriculture, especially in countries where regulation is poor. ${ }^{54}$ Despite these concerns, statistically significant decreases were observed in $\sum_{6} \mathrm{DDT}$ concentrations at all MONET sites except Brazzaville and Sheda, ranging from 6 to $16 \%$ annually $(p<0.05$; Figure $\left.1, \sum_{6} \mathrm{DDT}\right)$. The lack of statistical significance in the decline at Sheda was attributed to elevated concentrations of o,p'-DDT and p,p'-DDT in 10 samples between 2014 and 2016, indicative of fresh DDT application. Technical DDT formulations are primarily comprised of $\mathrm{p}, \mathrm{p}^{\prime}-\mathrm{DDT}$, with $\mathrm{p}, \mathrm{p}^{\prime}-\mathrm{DDE}$ being its main transformation product in the environment; thus, the ratio of these two compounds helps differentiate between emissions from fresh DDT application and revolatilization from secondary sources such as agricultural soil and sprayed buildings. ${ }^{9,50,52,54}$ Unsurprisingly, $\sum_{6} \mathrm{DDT}$ concentrations at some sites remain higher than those of any other POP, with modeled January 1, 2019, concentrations at Asela and Brazzaville as high as 138 and $87 \mathrm{pg} / \mathrm{m}^{3}$, respectively. Annual median concentrations were similarly elevated at Bamako (72 $\left.\mathrm{pg} / \mathrm{m}^{3}, 2018\right)$, Khartoum $\left(203 \mathrm{pg} / \mathrm{m}^{3}, 2014\right)$, and Rabat (72 pg/ $\left.\mathrm{m}^{3}, 2015\right)$. Apart from Asela, these sites are all in capital cities; thus, elevated concentrations are likely influenced by both historical use on surrounding agricultural land as well as modern use for public health. Modeled concentrations at the remaining sites ranged from $1.8 \mathrm{pg} / \mathrm{m}^{3}$ at Mt. Kenya to $16.7 \mathrm{pg} / \mathrm{m}^{3}$ at Abetefi. At all sites except Asela, the relative proportion of $\mathrm{p}, \mathrm{p}^{\prime}$ DDE contributing to $\sum_{6} \mathrm{DDT}$ now exceeds that of $\mathrm{p}, \mathrm{p}^{\prime}-\mathrm{DDT}$ (averages $41 \%$ and $27 \%$, respectively; Table S7E), suggesting no significant applications of fresh DDT and consistent with the observed decreasing trends. However, Asela had the highest relative proportion of $\mathrm{p}, \mathrm{p}^{\prime}$-DDT $(40 \%)$ which also exceeded that of $\mathrm{p}, \mathrm{p}^{\prime}$-DDE (29\%), indicating fresh emissions and consistent with the highest atmospheric $\sum_{6} \mathrm{DDT}$ concentrations still measured at this site. Ethiopia was previously identified as one of the major importers of DDT precursor chemicals to the continent and one of only two African countries where DDT was formulated (the other being South Africa) $;{ }^{9}$ increased usage of DDT since 2000 was also reported. ${ }^{31}$ As a result, the application, contamination, and stockpiles of DDT in Ethiopia are all expected to be highly elevated, but atmospheric concentrations have still decreased significantly over the past decade.

Endosulfan is frequently detected in the atmosphere across Africa, with maximum concentrations ranging 376-838 pg/ $\mathrm{m}^{3} .^{50-52}$ However, all previous sampling campaigns occurred when it was still widely in use, ${ }^{50-53,55}$ and as a result, the concentrations in the literature do not capture the effects of its listing in the SC in 2011. Endosulfan is therefore particularly useful for evaluating the effectiveness of regulatory measures across Africa, as it is the only POP that was sampled under MONET for several years prior to its listing. As a result, the steepest and most statistically significant temporal trends observed in this study were for $\sum_{3}$ endosulfan, with annual decreases ranging from 24 to $54 \%(p<0.01)$ at all sites (Figure 1, $\sum_{3}$ endosulfan). Thus, atmospheric concentrations of 
$\sum_{3}$ endosulfan are now one order of magnitude lower than those during the initial MONET campaign in 2008, ${ }^{9}$ with modeled January 1, 2019, concentrations ranging from $0.1 \mathrm{pg} / \mathrm{m}^{3}$ at Sheda to $24.3 \mathrm{pg} / \mathrm{m}^{3}$ at Asela. Technical endosulfan is $>95 \%$ comprised of two isomers $(\alpha$ and $\beta$ ); however, the ratios vary significantly depending on the formulation $(2: 1$ to $7: 3), \beta$ endosulfan may be irreversibly converted to $\alpha$-endosulfan, and both degrade to endosulfan sulfate in the environment. ${ }^{56}$ As a result, significant variability was observed in the relative profiles of these three analytes contributing to $\sum_{3}$ endosulfan concentrations at the MONET sites (Table S7F). The $\alpha$ isomer dominated at all sites, with relative proportions of nearly $100 \%$ at Mt. Kenya and Reduit (94-95\%), similar to profiles observed at remote sites in the Arctic. ${ }^{57}$ The $\alpha$ isomer is significantly more persistent in the atmosphere and capable of LRT in comparison to the $\beta$ isomer, ${ }^{56}$ consistent with previous conclusions of the influence of LRT on other POP concentrations at these two sites. Conversely, the highest contributions of the $\beta$ isomer were observed at Asela, Bamako, Khartoum, and Rabat (22-31\%), suggesting that the elevated $\sum_{3}$ endosulfan concentrations at these sites are the result of more recent applications. Finally, the proportions of endosulfan sulfate were significantly higher at Abetefi and Sheda (28-34\%) in comparison to all other sites $(2-8 \%)$. These two sites had some of the highest initial $\sum_{3}$ endosulfan concentrations, but also the steepest annual declines, suggesting that previous applications have since stopped.

Previous studies across Africa have found atmospheric concentrations of hexachlorocyclohexanes ( $\mathrm{HCHs}$ ) to be either similar to or lower than those of DDT and endosulfan, ${ }^{50,52,53}$ though high concentrations $\left(2720 \mathrm{pg} / \mathrm{m}^{3}\right)$ indicative of continued agricultural application have still been observed in some countries. ${ }^{54}$ However, steep and statistically significant decreasing trends $(12-33 \%, p<0.05)$ were also observed in $\sum_{4} \mathrm{HCH}$ concentrations at almost every MONET site (Figure 1, $\left.\sum_{4} \mathrm{HCH}\right)$. Modeled $\sum_{4} \mathrm{HCH}$ January 1, 2019, concentrations ranged from $0.6 \mathrm{pg} / \mathrm{m}^{3}$ at Sheda to $14.6 \mathrm{pg} / \mathrm{m}^{3}$ at Asela. Annual median concentrations at Bamako $\left(1.8 \mathrm{pg} / \mathrm{m}^{3}, 2018\right)$ and Rabat $\left(20.5 \mathrm{pg} / \mathrm{m}^{3}, 2015\right)$ fell within a similar range, but that at Khartoum was elevated $\left(54.7 \mathrm{pg} / \mathrm{m}^{3}, 2014\right)$. HCH was applied as two formulations: technical $\mathrm{HCH}$ was comprised of $60-70 \%$ $\alpha-\mathrm{HCH}$ (as well as $\beta, \gamma$, and $\delta$ ) and was used until it was replaced by the purified $\gamma$-HCH formulation (lindane). ${ }^{54}$ The $\gamma-\mathrm{HCH}$ isomer dominated at all sites except for Mt. Kenya, consistent with studies indicating that $\mathrm{HCH}$ emissions in Africa are primarily due to lindane. ${ }^{50,52-54}$ However, significant differences were still observed in the isomer profiles among the sites, with $\gamma-\mathrm{HCH}$ accounting for $81-88 \%$ of $\sum_{4} \mathrm{HCH}$ at Abetefi, Brazzaville, Reduit, and Sheda, suggesting the use of lindane alone (Table S7G). At the other sites, the contributions of $\alpha$ and $\beta$ - $\mathrm{HCH}$ were higher, suggesting revolatilization of older technical $\mathrm{HCH}$ from soils in addition to more recent applications of lindane.

Other POPs. Temporal trends and atmospheric concentrations of all other POPs included in this study are presented in Table 2 and are discussed in detail in section 4 (Other POPs) of the Supporting Information. In general, either no significant changes were observed in the concentrations of these POPs over the monitoring period or the data series were too short to determine trends with any certainty. In comparison to DDT, endosulfan, and $\mathrm{HCHs}$, no statistically significant change was observed in the concentrations of $\mathrm{HCB}$ or $\mathrm{PeCB}$ at any site except for a $5 \%$ decrease in $\mathrm{HCB}$ at Asela (Figure S2C).
Conversely, due to poor detection limits in the analysis of the "other" OCPs (aldrin, chlordane, dieldrin, endrin, heptachlor, and mirex) during the initial MONET sampling campaigns (2008-2012), data series for these compounds were relatively short, leading to greater uncertainty and no statistically significant temporal trends (Figure S2D-H). In general, trends suggest that concentrations of most of these "other" OCPs will decline over time or are so low that they represent a constant background level. Temporal trends for dl-PCBs were statistically insignificant due to the late addition of these compounds to routine MONET analysis (since 2014 at most sites) and showed a lack of change over time similar to that of the PCDD/Fs at most sites (Figure S2I). Similar to the case for the PBDEs, no statistically significant changes were observed in concentrations of HBCDD, except at Asela and Mt. Kenya, where they appear to be decreasing, though the confidence intervals are wide (Figure S2J). Chlordecone and hexabromobiphenyl were removed from routine analysis since concentrations consistently fell below the instrumental LOQ at all sites. PFOA and PFOS were also removed from analysis, though monitoring of PFOS continued at Mt. Kenya, where concentrations decreased $27 \%$ annually over 6 years (Figure S2K).

Sources of Sampled Air. Most MONET sites in Africa are in countries around the perimeter of the continent, with samplers at all but three sites (Asela, Bamako, and Khartoum) located less than $500 \mathrm{~km}$ from a coastline. Accordingly, modeled air mass back-trajectories at these sites mostly reflected ocean air currents, indicating that elevated concentrations observed at sites such as Abetefi and Brazzaville are likely the result of local emission sources rather than LRT from other countries (Figure 2 and Figure S3). These airflow patterns were highly consistent

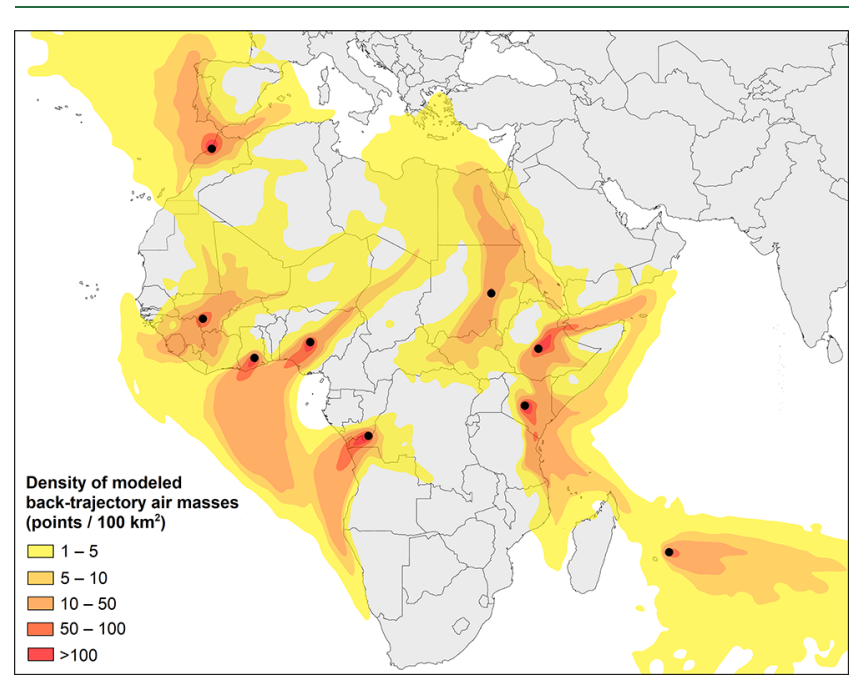

Figure 2. Density heat map of 120 -h back-trajectories for each MONET site in Africa modeled every $3 \mathrm{~h}$ for 365 days (JanuaryDecember 2018) using HYSPLIT (v.4.2.0, NOAA). ${ }^{26}$ Each individual 120 -h back-trajectory line was converted into 120 hourly air mass points. The density of these points within each $100 \mathrm{~km}^{2}$ grid cell across the continent accounts for both the total distance covered by each air mass and its residence time within each grid cell. Density values are semiquantitative and dependent on the rate of modeled release $(3 \mathrm{~h})$ and time resolution of air mass points (hourly). As such, they should be interpreted with caution and used solely to make visual comparisons of the total spatial coverage of each site. This density heat map depicts the sum of all 108 site-specific monthly back-trajectory aggregations presented in Figure S4. The map was created in ArcGIS (v.10.7, Esri). 
with previous meteorological analyses of airflow patterns across continental Africa. ${ }^{10,58}$ A detailed discussion of the seasonality of sources and monthly airflow patterns modeled at each site is provided in section 5 (Back-Trajectories) of the Supporting Information.

Modeled January 1, 2019, atmospheric concentrations of nearly all POPs were the highest at Brazzaville, with temporal trends also showing minimal change over the past decade, indicating significant ongoing emissions. This was unsurprising, as the sampler is located in the third largest urban and industrial center in Africa, Kinshasa-Brazzaville (adjacent capitals of Democratic Republic of Congo and Congo, Figure S4A). Furthermore, a MONET sampler was deployed in Kinshasa during the initial 2008 campaign and recorded some of the highest POP concentrations across the continent at the time. One of the other most notable local sources of POPs affecting the MONET network in Africa is the e-waste recycling site in Agbogbloshie, a suburb of Ghana's capital Accra, located approximately $140 \mathrm{~km} \mathrm{SE}$ of the sampler in Abetefi. Agbogbloshie is one of the largest and most polluted e-waste sites in the world and is one of the most significant point sources of POPs in Africa, and its effect on the surrounding environment and human population has been the subject of intense study. ${ }^{29,37,49,53,59-61}$ Abetefi had the second or third highest modeled January 1, 2019, concentrations of $\sum_{6} \mathrm{PCB}$, $\sum_{17} \mathrm{PCDD} / \mathrm{F}, \sum_{9} \mathrm{PBDE}$, and BDE 209. Since Abetefi is a rural background site, the high concentrations of these urban/ industrial POPs were likely the result of emissions from Agbogbloshie/Accra. However, nearly all modeled air masses sampled at Abetefi arrived exclusively from the southwest yearround over an extremely narrow geographic area; thus, Agbogbloshie appeared to be largely avoided. The only time when modeled air masses from Agbogbloshie appeared to reach Abetefi was November-January (Figure S4B), which may explain why POP concentrations at this site were lower than those that would otherwise be expected from direct emissions at Agbogbloshie. On the basis of the results of the back-trajectory analysis of Abetefi, as well as at Sheda further to the east in Nigeria (Figure S4C), atmospheric POP emissions from Agbogbloshie are instead expected to be primarily carried northeast across the rest of Accra year-round.

In comparison to the sites in coastal countries, the modeled air masses sampled at Bamako and Khartoum covered the largest geographic areas of continental Africa and are likely influenced by multiple sources, both local and abroad. Although the data at Bamako were insufficient to derive temporal trends, atmospheric concentrations of many POPs at this site were elevated, similarly to those measured at Brazzaville and Khartoum. The geographic coverage of modeled air masses sampled at Bamako changed drastically over the course of a year, with most airflows first passing over adjacent countries in Western Africa, where elevated PCB emissions have previously been observed, ${ }^{30}$ in addition to local sources previously identified in Bamako and elsewhere in Mali. ${ }^{9,10,62}$ However, during the Harmattan season this region of Western Africa instead receives airflows from the northeast, across the Sahara, that carry dust and airborne particles (approximately December-February, Figure S4D). This Saharan dust contains PCBs and $\mathrm{OCPs}^{62}$ and likely influences the concentrations measured at Bamako during this season.

Significant seasonal variations were also observed in the direction and sources of modeled air masses sampled at Khartoum, although some coverage of Egypt and the
Mediterranean from the north occurred year-round (Figure S4E). Although the concentrations of nearly all POPs included in this study were the highest at Khartoum, it is important to reiterate that monitoring at this site ended 5 years earlier than at the other sites. On the basis of the temporal trends, concentrations of many POPs are expected to be lower in 2019. However, while some local sources have previously been discussed at this site, ${ }^{9}$ the results of the back-trajectory analysis suggest that emission sources from Egypt, specifically Cairo, may in fact be the primary influence on POP concentrations measured at Khartoum. The greater Cairo area is the second largest urban and industrial center in Africa, contains 50\% of Egypt's industrial activity, and is surrounded by agricultural land. ${ }^{9,63}$ A MONET sampler was deployed in Cairo during the initial 2008 African campaign and measured most of the highest POP concentrations across the continent at the time, with PCDFs in particular at least 1 order of magnitude higher than those at all other sites and a recorded maximum of approximately $1000 \mathrm{fg} \mathrm{TEQ} / \mathrm{m}^{3}$.

Of the remaining sites, the lowest atmospheric concentrations were observed for most POPs at Mt. Kenya and Reduit. The sampler at Mt. Kenya is the most remote MONET site in Africa, located on the northern face of Mount Kenya at an elevation of $3680 \mathrm{~m}$. Although the capital of Nairobi is located only $140 \mathrm{~km}$ $\mathrm{SW}$, the site almost exclusively received airflows from either the NE or SE along the coast of East Africa and across the Indian Ocean year-round (Figure S4F). Thus, emission sources from Nairobi appear to be largely avoided. As a result, modeled January 1, 2019, concentrations of $\sum_{6} \mathrm{PCB}, \sum_{17} \mathrm{PCDD} / \mathrm{F}$, $\sum_{9}$ PBDE, BDE 209, and $\sum_{6}$ DDT at Mt. Kenya were all lower than those at every other site and likely reflect the continental background.

While temporal trends and concentrations at Reduit were similar to those at Mt. Kenya for most POPs, PBDEs and $\mathrm{PCDD} / \mathrm{Fs}$ were two major exceptions. In both cases, concentrations at all other sites showed no change over the entire monitoring period, whereas concentrations at Reduit either significantly decreased $\left(\sum_{9} \mathrm{PBDE}\right)$ or increased $\left(\sum_{17} \mathrm{PCDD} / \mathrm{F}\right)$. Reduit is a particularly useful site for evaluating the effectiveness of the Stockholm Convention, as it is the only site unaffected by emissions from other countries, with airflows arriving exclusively from over the Southern Ocean and no other major land masses year-round (Figure S4G). While the significant decrease in PBDEs therefore suggests some regulatory measures in Mauritius have been successful, the significant increase in PCDD/Fs demonstrates how easily local POP emissions can go undetected and further highlights the importance of long-term monitoring.

Implications for Future Monitoring. The significant decline in concentrations of some legacy POPs, such as DDT, endosulfan, and $\mathrm{HCHs}$, over the past decade clearly demonstrates that regulatory measures across Africa have been successful in reducing the atmospheric burden of these compounds, though illicit use and obsolete stockpiles continue to pose a challenge. Unfortunately, concentrations of other POPs such as PCDD/Fs and PBDEs have not changed significantly and are in fact increasing at some sites, likely due to the continued prevalence of open burning of waste (particularly e-waste). These results support previous studies indicating that primary emissions are still the dominant source of many POPs in Africa and highlight the need for continued monitoring. However, the sustainability of passive air monitoring in Africa is uncertain. Long-term collaboration with on-site 
partners is critical for the success of monitoring networks, but issues with funding, communication, and accessibility of sites have all reduced the stability and activity of the MONET network in Africa over the past 10 years. As a result, gaps now exist in the continental coverage of long-term monitoring, particularly in northern and southern Africa. Despite these concerns, this study validates the monitoring concept initially proposed by the Global Monitoring Plan: a new, continentalscale passive sampling network was established that now yields, a decade later, long-term trend data for a large set of POPs that can be used for evaluating the effectiveness of the Stockholm Convention in Africa. We therefore recommend that similar long-term trend analyses be performed for the other UN regions and propose the MONET network as a model for regions where atmospheric POP data are still too limited to evaluate the effectiveness of the Stockholm Convention.

\section{ASSOCIATED CONTENT}

\section{SI Supporting Information}

The Supporting Information is available free of charge at https://pubs.acs.org/doi/10.1021/acs.est.0c03575.

Details on sampling sites, temporal sampling regimes, analytical methods, contributions of individual compounds to groups of substances, temporal trends of POPs not presented in the main text, and airflow backtrajectories (PDF)

Trends and concentrations for individual compounds, as well as more detailed statistical results (XLSX)

\section{AUTHOR INFORMATION}

\section{Corresponding Authors}

Martin Scheringer - RECETOX, Masaryk University, 62500 Brno, Czech Republic; Institute of Biogeochemistry and Pollutant Dynamics, ETH Zürich, 8092 Zürich, Switzerland; () orcid.org/0000-0002-0809-7826;

Email: martin.scheringer@recetox.muni.cz

Jana Klánová - RECETOX, Masaryk University, 62500 Brno, Czech Republic; (i) orcid.org/0000-0002-8818-5307;

Email: jana.klanova@recetox.muni.cz

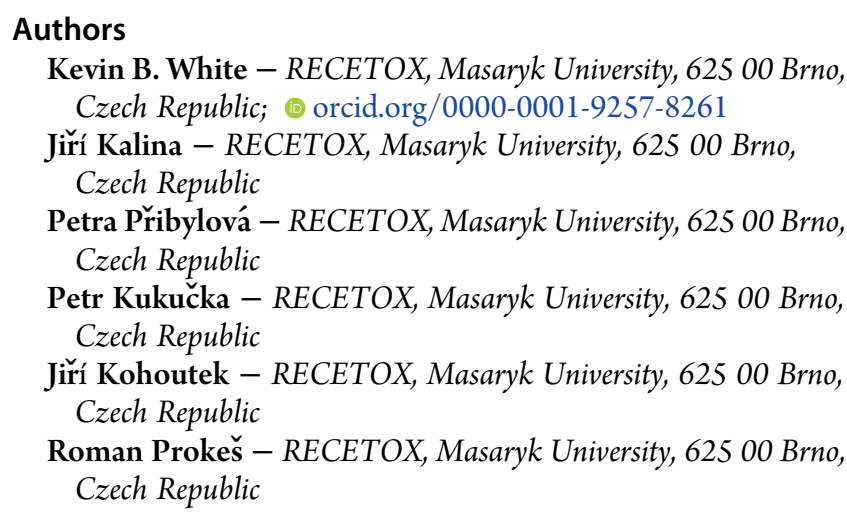

Complete contact information is available at:

https://pubs.acs.org/10.1021/acs.est.0c03575

\section{Notes}

The authors declare no competing financial interest.

\section{ACKNOWLEDGMENTS}

We sincerely thank all of our monitoring partners across Africa, without whom the MONET network would not be possible, including Jean de Dieu Nzila (Congo), Sam Adu-Kumi and Crentsil Kofi Bempah (Ghana), Habtamu Wodajo Wolde (Ethiopia), Vincent Odongo Madadi (Kenya), Halimatou Koné Traoré and Boubacar Madio dit Aladiogo Maiga (Mali), Sheba Rojubally Cadinouche and Michael Tsang (Mauritius), Anas Otmani and Mohammed El Bouch (Morocco), Stella Uchenna Mojekwu and Abdul-Ganiyu Yunuss (Nigeria), and Sit Nour Hassan Mohamed Hassan (Sudan). We also wish to thank all RECETOX staff who have contributed to the success of the MONET network in Africa over the past 10 years, including Kateřina Šebková, Jana Borůvková, Ondřej Audy, Zdenka Bednářová, Pavlina Karásková, Anton Kočan, Jakub Martiník, and Petr Senk, as well as Gerhard Lammel, Céline Degrendele, and Ondřej Sáňka for their guidance in the modeling and mapping of back-trajectories in HYSPLIT and ArcGIS. We also acknowledge Katarina Magulová and Ana-Maria Witt from the Secretariat of the Stockholm Convention on Persistent Organic Pollutants for their continuous support of monitoring activities by the MONET network in Africa. This work was supported by the EU Horizon 2020 programme (ERA PLANET, 689443; eSHAPE, 820852; CETOCOEN EXCELLENCE TEAMING, 2857560), the Czech Ministry of Education, Youth and Sports (RECETOX RI, LM2018121), and the European Structural and Investment Funds (CETOCOEN EXCELLENCE TEAMING 2, CZ.02.1.01/0.0/0.0/17_043/0009632; CETOCOEN PLUS, CZ.02.1.01/0.0/0.0/15_003/0000469). Funding for the implementation of the Global Monitoring Plan on Persistent Organic Pollutants in Africa was also provided by the Stockholm Convention Secretariat (UNEP/PCA/SSC/2014/8, BRS-SSCSSFA-1615 and BRS-SSC-SSFA-1731).

\section{REFERENCES}

(1) Gioia, R.; Akindele, A. J.; Adebusoye, S. A.; Asante, K. A.; Tanabe, S.; Buekens, A.; Sasco, A. J. Polychlorinated Biphenyls (PCBs) in Africa: A Review of Environmental Levels. Environ. Sci. Pollut. Res. 2014, 21 (10), 6278-6289.

(2) Pius, C.; Sichilongo, K.; Koosaletse Mswela, P.; Dikinya, O. Monitoring Polychlorinated Dibenzo-p-Dioxins/Dibenzofurans and Dioxin-like Polychlorinated Biphenyls in Africa since the Implementation of the Stockholm Convention-an Overview. Environ. Sci. Pollut. Res. 2019, 26 (1), 101-113.

(3) Ssebugere, P.; Sillanpää, M.; Matovu, H.; Mubiru, E. Human and Environmental Exposure to PCDD/Fs and Dioxin-like PCBs in Africa: A Review. Chemosphere 2019, 223, 483-493.

(4) Brits, M.; de Vos, J.; Weiss, J. M.; Rohwer, E. R.; de Boer, J. Critical Review of the Analysis of Brominated Flame Retardants and Their Environmental Levels in Africa. Chemosphere 2016, 164, 174-189.

(5) Katima, Z.; Okonkwo, J. O.; Daso, A. P. A Review of Brominated Flame Retardants in the Environment with Emphasis on Atmospheric Levels, Knowledge and Information Gaps in the African Continent. Atmos. Pollut. Res. 2017, 8 (4), 767-780.

(6) Taiwo, A. M. A Review of Environmental and Health Effects of Organochlorine Pesticide Residues in Africa. Chemosphere 2019, 220, $1126-1140$.

(7) Olisah, C.; Okoh, O. O.; Okoh, A. I. Occurrence of Organochlorine Pesticide Residues in Biological and Environmental Matrices in Africa: A Two-Decade Review. Heliyon 2020, 6 (3), No. e03518.

(8) Pribylova, P.; Kares, R.; Boruvkova, J.; Cupr, P.; Prokes, R.; Kohoutek, J.; Holoubek, I.; Klanova, J. Levels of Persistent Organic Pollutants and Polycyclic Aromatic Hydrocarbons in Ambient Air of Central and Eastern Europe. Atmos. Pollut. Res. 2012, 3 (4), 494-505.

(9) Klánová, J.; Čupr, P.; Holoubek, I.; Borůvková, J.; Přibylová, P.; Kareš, R.; Tomej, T.; Ocelka, T. Monitoring of Persistent Organic Pollutants in Africa. Part 1: Passive Air Sampling across the Continent in 2008. J. Environ. Monit. 2009, 11 (11), 1952-1963. 
(10) Lammel, G.; Dobrovolný, P.; Dvorská, A.; Chromá, K.; Brázdil, R.; Holoubek, I.; Hoek, J. Monitoring of Persistent Organic Pollutants in Africa. Part 2: Design of a Network to Monitor the Continental and Intercontinental Background. J. Environ. Monit. 2009, 11 (11), 19641972.

(11) Klánová, J.; Harner, T. The Challenge of Producing Reliable Results under Highly Variable Conditions and the Role of Passive Air Samplers in the Global Monitoring Plan. TrAC - Trends Anal. Chem. 2013, 46, 139-149.

(12) Kalina, J.; Scheringer, M.; Borůvková, J.; Kukučka, P.; Přibylová, P.; Bohlin-Nizzetto, P.; Klánová, J. Passive Air Samplers As a Tool for Assessing Long-Term Trends in Atmospheric Concentrations of Semivolatile Organic Compounds. Environ. Sci. Technol. 2017, 51 (12), 7047-7054.

(13) Kalina, J.; White, K. B.; Scheringer, M.; Přibylová, P.; Kukučka, P.; Audy, O.; Klánová, J. Comparability of Long-Term Temporal Trends of POPs from Co-Located Active and Passive Air Monitoring Networks in Europe. Environ. Sci. Process. Impacts 2019, 21 (7), 11321142.

(14) Bohlin-Nizzetto, P.; Melymuk, L.; White, K. B.; Kalina, J.; Madadi, V. O.; Adu-Kumi, S.; Prokeš, R.; Přibylová, P.; Klánová, J. Field- and Model-Based Calibration of Polyurethane Foam Passive Air Samplers in Different Climate Regions Highlights Differences in Sampler Uptake Performance. Atmos. Environ. 2020, 238, 117742.

(15) Pozo, K.; Harner, T.; Wania, F.; Muir, D. C. G.; Jones, K. C.; Barrie, L. A. Toward a Global Network for Persistent Organic Pollutants in Air: Results from the GAPS Study. Environ. Sci. Technol. 2006, 40 (16), 4867-4873.

(16) Pozo, K.; Harner, T.; Lee, S. C.; Wania, F.; Muir, D. C. G.; Jones, K. C. Seasonally Resolved Concentrations of Persistent Organic Pollutants in the Global Atmosphere from the First Year of the GAPS Study. Environ. Sci. Technol. 2009, 43 (3), 796-803.

(17) Shunthirasingham, C.; Oyiliagu, C. E.; Cao, X.; Gouin, T.; Wania, F.; Lee, S. C.; Pozo, K.; Harner, T.; Muir, D. C. G. Spatial and Temporal Pattern of Pesticides in the Global Atmosphere. J. Environ. Monit. 2010, 12 (9), 1650-1657.

(18) UNEP. Global Monitoring Plan for Persistent Organic Pollutants: First Regional Monitoring Report - Africa Region. UNEPPOPS-GMP-RMR-AFR, 2009.

(19) UNEP. Global Monitoring Plan for Persistent Organic Pollutants: Second Regional Monitoring Report - Africa Region. UNEP-POPS-GMP-RMR-AFRICA-2015 2015.

(20) Wöhrnschimmel, H.; Scheringer, M.; Bogdal, C.; Hung, H.; Salamova, A.; Venier, M.; Katsoyiannis, A.; Hites, R. A.; Hungerbuhler, K.; Fiedler, H. Ten Years after Entry into Force of the Stockholm Convention: What Do Air Monitoring Data Tell about Its Effectiveness? Environ. Pollut. 2016, 217, 149-158.

(21) Borůvková, J.; Gregor, J.; Šebková, K.; Bednárová, Z.; Kalina, J.; Hůlek, R.; Dušek, L.; Holoubek, I.; Klánová, J. GENASIS - Global Environmental Assessment and Information System; http://www. genasis.cz (accessed July 24, 2019).

(22) Saini, A.; Clarke, J.; Harner, T. Direct measurements of polyurethane foam (PUF) - air partitioning coefficients for chemicals of emerging concern capable of equilibrating in PUF disk samplers. Chemosphere 2019, 234, 925-930.

(23) Gelaro, R.; McCarty, W.; Suárez, M. J.; Todling, R.; Molod, A.; Takacs, L.; Randles, C. A.; Darmenov, A.; Bosilovich, M. G.; Reichle, R.; Wargan, K.; Coy, L.; Cullather, R.; Draper, C.; Akella, S.; Buchard, V.; Conaty, A.; da Silva, A. M.; Gu, W.; Kim, G. K.; Koster, R.; Lucchesi, R.; Merkova, D.; Nielsen, J. E.; Partyka, G.; Pawson, S.; Putman, W.; Rienecker, M.; Schubert, S. D.; Sienkiewicz, M.; Zhao, B. The ModernEra Retrospective Analysis for Research and Applications, Version 2 (MERRA-2). J. Clim. 2017, 30 (14), 5419-5454.

(24) Herkert, N. J.; Spak, S. N.; Smith, A.; Schuster, J. K.; Harner, T.; Martinez, A.; Hornbuckle, K. C. Calibration and Evaluation of PUFPAS Sampling Rates across the Global Atmospheric Passive Sampling (GAPS) Network. Environ. Sci. Process. Impacts 2018, 20 (1), 210-219. (25) Sebková, K.; Gregor, J.; Hůlek, R.; Borůvková, J.; Kalina, J.; Salko, M.; Novák, R.; Klánová, J. User Guide on Global Monitoring Plan Data
Warehouse for Data Providers and Users, Version 3; Masaryk University: Brno, Czech Republic, 2015.

(26) Stein, A. F.; Draxler, R. R.; Rolph, G. D.; Stunder, B. J.; Cohen, M. D.; Ngan, F. NOAA's HYSPLIT Atmospheric Transport and Dispersion Modeling System. Bull. Am. Meteorol. Soc. 2015, 96, 2059-2078.

(27) Lammel, G.; Heil, A.; Stemmler, I.; Dvorská, A.; Klánová, J. On the Contribution of Biomass Burning to POPs (PAHs and PCDDs) in Air in Africa. Environ. Sci. Technol. 2013, 47 (20), 11616-11624.

(28) Arinaitwe, K.; Muir, D. C. G.; Kiremire, B. T.; Fellin, P.; Li, H.; Teixeira, C.; Mubiru, D. N. Prevalence and Sources of Polychlorinated Biphenyls in the Atmospheric Environment of Lake Victoria, East Africa. Chemosphere 2018, 193, 343-350.

(29) Hogarh, J. N.; Seike, N.; Kobara, Y.; Carboo, D.; Fobil, J. N.; Masunaga, S. Source Characterization and Risk of Exposure to Atmospheric Polychlorinated Biphenyls (PCBs) in Ghana. Environ. Sci. Pollut. Res. 2018, 25 (17), 16316-16324.

(30) Gioia, R.; Eckhardt, S.; Breivik, K.; Jaward, F. M.; Prieto, A.; Nizzetto, L.; Jones, K. C. Evidence for Major Emissions of PCBs in the West African Region. Environ. Sci. Technol. 2011, 45 (4), 1349-1355.

(31) Bogdal, C.; Scheringer, M.; Abad, E.; Abalos, M.; Van Bavel, B.; Hagberg, J.; Fiedler, H. Worldwide Distribution of Persistent Organic Pollutants in Air, Including Results of Air Monitoring by Passive Air Sampling in Five Continents. TrAC, Trends Anal. Chem. 2013, 46, 150161.

(32) Breivik, K.; Armitage, J. M.; Wania, F.; Sweetman, A. J.; Jones, K. C. Tracking the Global Distribution of Persistent Organic Pollutants Accounting for E-Waste Exports to Developing Regions. Environ. Sci. Technol. 2016, 50 (2), 798-805.

(33) Breivik, K.; Sweetman, A.; Pacyna, J. M.; Jones, K. C. Towards a Global Historical Emission Inventory for Selected PCB Congeners - A Mass Balance Approach: 2. Emissions. Sci. Total Environ. 2002, 290 (1-3), 199-224.

(34) Breivik, K.; Sweetman, A.; Pacyna, J. M.; Jones, K. C. Towards a Global Historical Emission Inventory for Selected PCB Congeners - A Mass Balance Approach: 1. Global Production and Consumption. Sci. Total Environ. 2002, 290 (1-3), 181-198.

(35) Nøst, T. H.; Halse, A. K.; Schlabach, M.; Bäcklund, A.; Eckhardt, S.; Breivik, K. Low Concentrations of Persistent Organic Pollutants (POPs) in Air at Cape Verde. Sci. Total Environ. 2018, 612, 129-137.

(36) Moussaoui, Y.; Tuduri, L.; Kerchich, Y.; Meklati, B. Y.; Eppe, G. Atmospheric Concentrations of PCDD/Fs, Dl-PCBs and Some Pesticides in Northern Algeria Using Passive Air Sampling. Chemosphere 2012, 88 (3), 270-277.

(37) Tue, N. M.; Goto, A.; Takahashi, S.; Itai, T.; Asante, K. A.; Kunisue, T.; Tanabe, S. Release of Chlorinated, Brominated and Mixed Halogenated Dioxin-Related Compounds to Soils from Open Burning of e-Waste in Agbogbloshie (Accra, Ghana). J. Hazard. Mater. 2016, 302, 151-157.

(38) Schuster, J. K.; Harner, T.; Fillmann, G.; Ahrens, L.; Altamirano, J. C.; Aristizábal, B.; Bastos, W.; Castillo, L. E.; Cortés, J.; Fentanes, O.; Gusev, A.; Hernandez, M.; Ibarra, M. V.; Lana, N. B.; Lee, S. C.; Martínez, A. P.; Miglioranza, K. S. B.; Puerta, A. P.; Segovia, F.; Siu, M.; Tominaga, M. Y. Assessing Polychlorinated Dibenzo- $\mathrm{p}$-Dioxins and Polychlorinated Dibenzofurans in Air across Latin American Countries Using Polyurethane Foam Disk Passive Air Samplers. Environ. Sci. Technol. 2015, 49 (6), 3680-3686.

(39) Dopico, M.; Gómez, A. Review of the Current State and Main Sources of Dioxins around the World. J. Air Waste Manage. Assoc. 2015, 65 (9), 1033-1049.

(40) Brubaker, W. W.; Hites, R. A. Polychlorinated Dibenzo-pDioxins and Dibenzofurans: Gas-Phase Hydroxyl Radical Reactions and Related Atmospheric Removal. Environ. Sci. \& Technol. 1997, 31 (6), 1805-1810.

(41) Sinkkonen, S.; Paasivirta, J. Degradation Half-Life Times of PCDDs, PCDFs and PCBs for Environmental Fate Modeling. Chemosphere 2000, 40 (9-11), 943-949.

(42) Rauert, C.; Schuster, J. K.; Eng, A.; Harner, T. Global Atmospheric Concentrations of Brominated and Chlorinated Flame 
Retardants and Organophosphate Esters. Environ. Sci. Technol. 2018, 52 (5), 2777-2789.

(43) Arinaitwe, K.; Muir, D. C. G.; Kiremire, B. T.; Fellin, P.; Li, H.; Teixeira, C. Polybrominated Diphenyl Ethers and Alternative Flame Retardants in Air and Precipitation Samples from the Northern Lake Victoria Region, East Africa. Environ. Sci. Technol. 2014, 48 (3), 14581466.

(44) Katima, Z. J.; Olukunle, O. I.; Kalantzi, O.-1.; Daso, A. P.; Okonkwo, J. O. The Occurrence of Brominated Flame Retardants in the Atmosphere of Gauteng Province, South Africa Using Polyurethane Foam Passive Air Samplers and Assessment of Human Exposure. Environ. Pollut. 2018, 242, 1894-1903.

(45) La Guardia, M. J.; Hale, R. C.; Harvey, E. Detailed Polybrominated Diphenyl Ether (PBDE) Congener Composition of the Widely Used Penta-, Octa-, and Deca-PBDE Technical FlameRetardant Mixtures. Environ. Sci. Technol. 2006, 40 (20), 6247-6254.

(46) Li, J.; Li, Q.; Gioia, R.; Zhang, Y.; Zhang, G.; Li, X.; Spiro, B.; Bhatia, R. S.; Jones, K. C. PBDEs in the Atmosphere over the Asian Marginal Seas, and the Indian and Atlantic Oceans. Atmos. Environ. 2011, 45 (37), 6622-6628.

(47) Lohmann, R.; Klanova, J.; Kukucka, P.; Yonis, S.; Bollinger, K. Concentrations, Fluxes, and Residence Time of PBDEs Across the Tropical Atlantic Ocean. Environ. Sci. Technol. 2013, 47, 13967.

(48) Redfern, F. M.; Lee, W.-J.; Yan, P.; Mwangi, J. K.; Wang, L.-C.; Shih, C.-H. Overview and Perspectives on Emissions of Polybrominated Diphenyl Ethers on a Global Basis: Evaporative and Fugitive Releases from Commercial PBDE Mixtures and Emissions from Combustion Sources. Aerosol Air Qual. Res. 2017, 17, 1117-1131.

(49) Akortia, E.; Olukunle, O. I.; Daso, A. P.; Okonkwo, J. O. Soil Concentrations of Polybrominated Diphenyl Ethers and Trace Metals from an Electronic Waste Dump Site in the Greater Accra Region, Ghana: Implications for Human Exposure. Ecotoxicol. Environ. Saf. 2017, 137, 247-255.

(50) Arinaitwe, K.; Kiremire, B. T.; Muir, D. C. G.; Fellin, P.; Li, H.; Teixeira, C.; Mubiru, D. N. Legacy and Currently Used Pesticides in the Atmospheric Environment of Lake Victoria, East Africa. Sci. Total Environ. 2016, 543, 9-18.

(51) Isogai, N.; Hogarh, J. N.; Seike, N.; Kobara, Y.; Oyediran, F.; Wirmvem, M. J.; Ayonghe, S. N.; Fobil, J.; Masunaga, S. Atmospheric Monitoring of Organochlorine Pesticides across Some West African Countries. Environ. Sci. Pollut. Res. 2018, 25 (32), 31828-31835.

(52) Adu-Kumi, S.; Kareš, R.; Literák, J.; Borůvková, J.; Yeboah, P. O.; Carboo, D.; Akoto, O.; Darko, G.; Osae, S.; Klánová, J. Levels and Seasonal Variations of Organochlorine Pesticides in Urban and Rural Background Air of Southern Ghana. Environ. Sci. Pollut. Res. 2012, 19 (6), 1963-1970.

(53) Hogarh, J. N.; Seike, N.; Kobara, Y.; Ofosu-Budu, G. K.; Carboo, D.; Masunaga, S. Atmospheric Burden of Organochlorine Pesticides in Ghana. Chemosphere 2014, 102, 1-5.

(54) Isogai, N.; Hogarh, J. N.; Seike, N.; Kobara, Y.; Oyediran, F.; Wirmvem, M. J.; Ayonghe, S. N.; Fobil, J.; Masunaga, S. Atmospheric Monitoring of Organochlorine Pesticides across Some West African Countries. Environ. Sci. Pollut. Res. 2018, 25 (32), 31828-31835.

(55) Shunthirasingham, C.; Oyiliagu, C. E.; Lei, Y. D.; Wania, F.; Mmereki, B. T.; Masamba, W. Fate of Pesticides in the Arid Subtropics, Botswana, Southern Africa. Environ. Sci. Technol. 2010, 44 (21), 80828088.

(56) Weber, J.; Halsall, C. J.; Muir, D.; Teixeira, C.; Small, J.; Solomon, K.; Hermanson, M.; Hung, H.; Bidleman, T. Endosulfan, a Global Pesticide: A Review of Its Fate in the Environment and Occurrence in the Arctic. Sci. Total Environ. 2010, 408 (15), 29662984.

(57) Hung, H.; Kallenborn, R.; Breivik, K.; Su, Y.; Brorström-Lundén, E.; Olafsdottir, K.; Thorlacius, J. M.; Leppänen, S.; Bossi, R.; Skov, H.; Manø, S.; Patton, G. W.; Stern, G.; Sverko, E.; Fellin, P. Atmospheric Monitoring of Organic Pollutants in the Arctic under the Arctic Monitoring and Assessment Programme (AMAP): 1993-2006. Sci. Total Environ. 2010, 408 (15), 2854-2873.
(58) Leroux, M. The Meteorology and Climate of Tropical Africa, 1st ed.; Springer: Berlin, 2001.

(59) Wittsiepe, J.; Fobil, J. N.; Till, H.; Burchard, G. D.; Wilhelm, M.; Feldt, T. Levels of Polychlorinated Dibenzo-p-Dioxins, Dibenzofurans (PCDD/Fs) and Biphenyls (PCBs) in Blood of Informal e-Waste Recycling Workers from Agbogbloshie, Ghana, and Controls. Environ. Int. 2015, 79, 65-73.

(60) Bruce-Vanderpuije, P.; Megson, D.; Reiner, E. J.; Bradley, L.; Adu-Kumi, S.; Gardella, J. A. The State of POPs in Ghana- A Review on Persistent Organic Pollutants: Environmental and Human Exposure. Environ. Pollut. 2019, 245, 331-342.

(61) Asamoah, A.; Essumang, D. K.; Muff, J.; Kucheryavskiy, S. V.; Søgaard, E. G. Assessment of PCBs and Exposure Risk to Infants in Breast Milk of Primiparae and Multiparae Mothers in an Electronic Waste Hot Spot and Non-Hot Spot Areas in Ghana. Sci. Total Environ. 2018, 612, 1473-1479.

(62) Garrison, V. H.; Majewski, M. S.; Foreman, W. T.; Genualdi, S. A.; Mohammed, A.; Massey Simonich, S. L. Persistent Organic Contaminants in Saharan Dust Air Masses in West Africa, Cape Verde and the Eastern Caribbean. Sci. Total Environ. 2014, 468-469, 530543.

(63) Mansour, S. A. Persistent Organic Pollutants (POPs) in Africa: Egyptian Scenario. Hum. Exp. Toxicol. 2009, 28 (9), 531-566. 